\title{
The research of SBR process for LAS waste water treatment
}

\author{
Wenyuan Tan ${ }^{\mathrm{a}}$, Liangqin Zhou ${ }^{\mathrm{b}}$, Dayou Fu ${ }^{\mathrm{c}}$, Yuqin Chen ${ }^{\mathrm{d}}$ \\ Sichuan University of Science \& Engineering, Analysis and Testing, ZiGong, 64300, China. \\ atwyhyx@126.com, b2652828379@qq.com, cfdy888@263.net, d773564685@qq.com
}

Keywords: Activated sludge, Microbial acclimation, SBR, LAS, Wastewater treatment.

\begin{abstract}
The treatment of the waste water containing Linear Alkyl benzene sulphonate (LAS) was studied by the Sequencing Batch Reacto r(SBR)activated sludge process. The activated sludge was domesticated to get the micro biome which had a prominent degradation effect on the LAS. Simulated the SBR and find the effects of aeration rate, sedimentation time, $\mathrm{pH}$, metal ion on the LAS degradation of the activated sludge, and got a preliminary study of organic matter degradation kinetic in SBR. It shows that the LAS concentration levels reached $12 \mu \mathrm{g} \cdot \mathrm{mL}^{-1}$ in the SBR reactor, the best aeration rate is $0.2 \mathrm{~m}^{3} \cdot \mathrm{h}^{-1}$, the best sedimentation time is $12 \mathrm{~h}$ and $\mathrm{pH}$ value is 7 , the removal rate of LAS reach $81 \% . \mathrm{K}^{+}, \mathrm{Fe}^{2+}, \mathrm{Mg}^{2+}$ and $\mathrm{Ca}^{2+}$ can restrain the LAS degradation of the activated sludge in different degrees, but $\mathrm{Mg}^{2+}, \mathrm{Ca}^{2+}$ can slightly restrain the LAS degradation of the activated sludge, the removal rate of LAS reach $87 \%$. The activated sludge's organic matter degradation kinetic is $\mathrm{v}=1.01 \times 10^{-4} \mathrm{XS} /(1.011+\mathrm{S})$.
\end{abstract}

\section{Introduction}

Currently, the demand of global Surfactant has reached 11.3 milion tons, the total market value is about 30.3 billion dollars. LAS, huge annual output, is one of the most important anionic surfactants (JU,et al.,2014). LAS can enter natural water and soil through various channels, causing various pollution of environment and having certain toxic effects (Hampel et al., 2009; Henning et al., 2007; Ezemonye et al., 2009) on human body and biology. Water pollution has seriously degrade human beings causing direct harm to human and animal's body and health, so to solve the problem has become the focus for the global scientists (Zhang et al.,2013; Mauffret et al.,2011).Batch activated sludge process(SBR)with simple composition and the low cost of construction and operation (Wang et al.,2013; Gabarró et al.,2013), is a common biological treatment technology, which is mainly composed of sewage inflow, aeration, sludge, sewage discharge and system standby five component processes, are in the implementation of the aeration tank, so the SBR system without having to set up the sludge back flow device, no secondary sedimentation tank. Environmental treatment of waste water containing anion surfactant with SBR process was investigated byYu Xiao Cai etal (Yu et al.,2006). When concentration of LAS is $100 \mathrm{mg} / \mathrm{L}$ at the room temperature $-20{ }^{\circ} \mathrm{C}$, aeration time is $4.5 \mathrm{~h}$, sedimentation time is $2 \mathrm{~h}$,idle time is $0.5 \mathrm{~h}$, volume ration of sludge and water is $30 \%, \mathrm{pH}$ is 7 , the removal rate of LAS can reach $96.39 \%$. The process of domestication through the artificial addition of inducer in the party continue to stimulate and improve the yield of enzyme induced enzyme microbial cells, finally obtain high tolerance and activity strains (Benjamin et al.,2015; Tiyasha et al.,2015; Lin et al.,2015; Aamer et al.,2015), is a method of direct breeding microorganism. Therefore, this experiment will be adding LAS as"induction" approach to the acclimated activated sludge microorganism in to improve enzyme production of enzyme induced degradation of LAS cells. And in order to improve the ability of the degradation of LAS, and to study the kinetics of LAS degradation, the LAS as the carbon resource, under the condition of activated sludge, increase gradually in concentration. 


\section{Material and methods}

\subsection{Experimental materials}

The activated sludge was collected from aeration tank of sewage treatment plant in Zigong city, China; LAS wastewater was self-prepared; Microbial nutrient solution (LB solution):0.25\% $\mathrm{NaCl}, 0.125 \%$ beef extract, $0.25 \%$ peptone made into $3 \mathrm{~L}$ solution; LAS was made into $100 \mathrm{mg} . \mathrm{L}^{-1}$ reserving liquid and kept at $4{ }^{\circ} \mathrm{C}$; Methylene blue solution:50 g NaH $\mathrm{PO}_{4} . \mathrm{H} 2 \mathrm{O}$ dissolved in $300 \mathrm{~mL}$ water, and then $6.8 \mathrm{~mL}$ concentrated sulfuric acid and $30 \mathrm{mg}$ methylene blue slowly added, solution constant volume was $1 \mathrm{~L}$ in a brown flask.

\subsection{Laboratory equipment}

Lambda 35 UV / VIS double beam scanning full band spectrophotometer, PerkinElmer USA; pHS-4C ${ }^{+}$

Acidometer, century ark Science technology Chengdu China; FA1004 electric balance, hengping scientific instrument Shanghai, China; LZB glass rotor flow meter, automation instrument Tianjing,

China; Self-acclimated activated sludge system.

\subsection{Sludge acclimation}

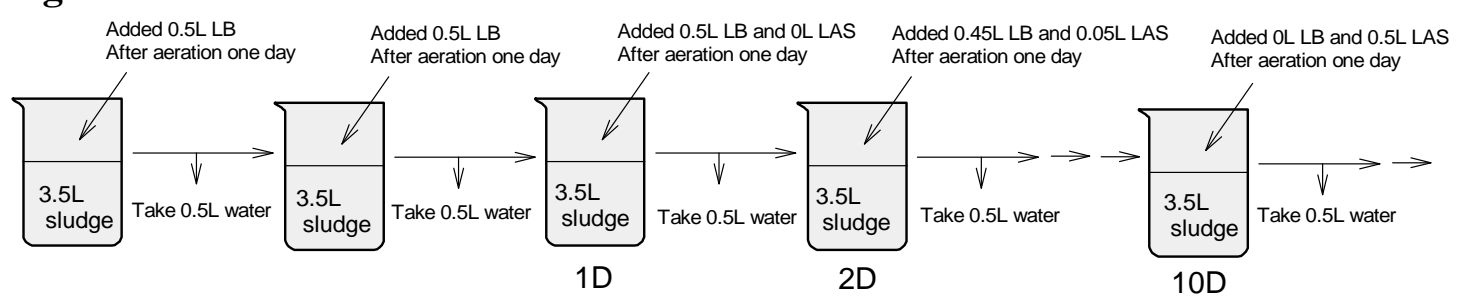

Fig. 1 The picture of activated sludge was domesticated

As shown in figure 1, the sludge was put into the rcator and trained for two days. Then the acclimatization training started, $0.5 \mathrm{~L}$ LB solution and without LAS added into the rcator in the first day, aeration for a day, the $0.5 \mathrm{~L}$ supernatant liquid was taken and $0.45 \mathrm{~L} \mathrm{LB}$ solution with $0.05 \mathrm{~L}$ LAS $\left(100 \mu \mathrm{g} \bullet \mathrm{mL}^{-1}\right)$ added in the second day, and so on, $0 \mathrm{~L} \mathrm{LB}$ solution with $0.5 \mathrm{~L} \mathrm{LAS}$ added in the tenth day.Ten days later, 0.5L LAS added and $0.5 \mathrm{~L}$ supernatant liquid was taken everyday, untill then the LAS concentration of the supernatant liquid was basically stable.

\section{4 measuring methods}

The complexing reaction occurs between Methylene blue and anionic detergents in aqueous solution, and formed blue complex was called methylene blue active substance (MBAS). The MBAS was extracted by chloroform and measured the absorbance of the chloroform layer at the wavelength of $652 \mathrm{~nm}$ by the spectro photometer for its color is proportional to the concentration, so as to the content of anionic detergents can be calculated. The effects of organic acid salt on the determination results eliminated by the water back washing.

The SV refers to the sludge setting ratio, MLSS refers to the concentration of suspend solid in mixed liquid, and the unit is $\mathrm{mg} \cdot \mathrm{L}^{-1}$.In general, the higher the MLSS value, the more the microbial population, the higher the SV, the better the microbial nutrition environment,and the sludge is fat,good flocculation. The MLSS and SV were determinated every day in the period of acclimation of activated sludge.

\section{$\mathrm{SV}=\mathrm{V}_{0} / \mathrm{V}_{1} \times 100 \% \quad . \mathrm{MLSS}=\left(\mathrm{m}_{1}-\mathrm{m}_{2}\right) / \mathrm{V}_{1}$}

Of which, $\mathrm{V}_{1}$ refers to the volume of the mixed activated sludge which is taken out of the aeration process; $\mathrm{V}_{0}$ is the volume of sludge after $30 \mathrm{~min}$ deposition; $\mathrm{M}_{1}$ is the filter quality after drying to constant weight; $\mathrm{M}_{2}$ refers to the quality of filter paper and dried to a constant weight of sludge. 


\section{The results and analysis}

\subsection{The culture of activated sludge}

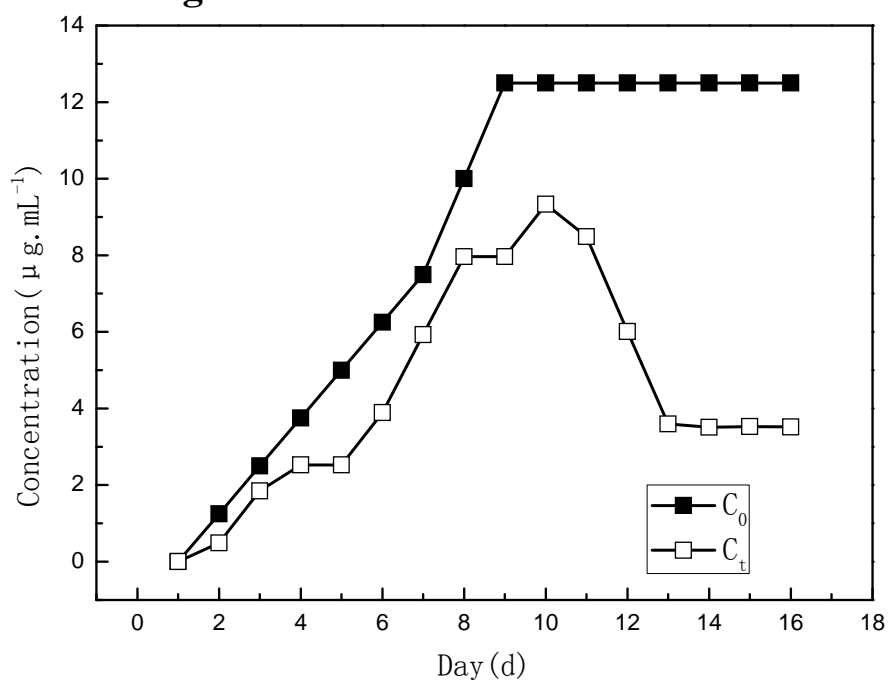

Fig.2 Influence of incubation time on LAS removal efficiency

As shown in figure 2 , in order to improve enzyme production of enzyme induced degradation of LAS in the cells,after the addition of LAS as "inducer" approach to the acclimated activated sludge microorganisms .In this experiment, LAS as the carbon source, the activated sludge was domesticated under the condition of LAS concentration was gradual increased, in order to improve its ability to degrade LAS. After 15 days of cultivation, the ability of active sludge degradation of LAS was gradually increased tended to be stable from the thirteenth day, the removal rate of LAS is stable at $72 \%$.

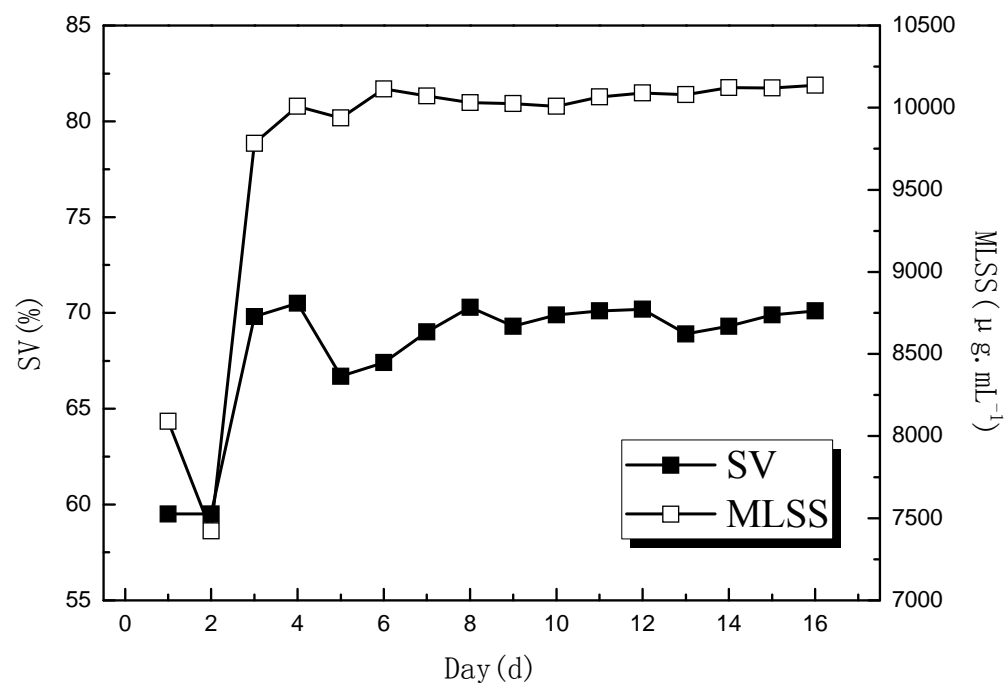

Fig3. The SV and MLSS of achieved activated sludge

As shown in figure 3, the change of SV and MLSS of the activated sludge after the addition of LB and LAS solution. SV gradually increased to a stable, which showed that the concentration of sludge increased after incubation.The MLSS value of activated sludge increased gradually from the beginning, to gradually stable, the higher the MLSS, the higher the sludge concentration, also indicated that the higher the activity of the sludge in the sludge, the better purification effect. 


\subsection{The effect of $\mathrm{pH}$ value}

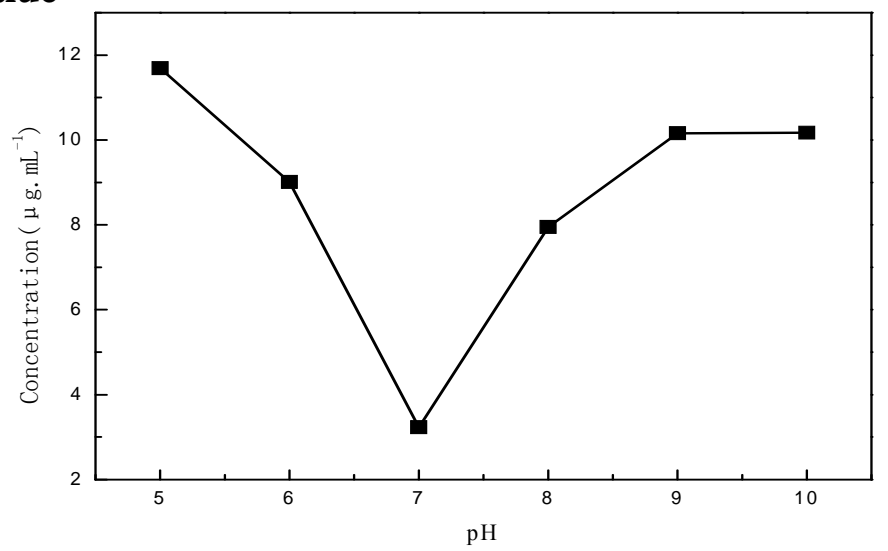

Fig.4 Influence of $\mathrm{pH}$ on LAS removal efficiency

Under the experimental conditions, adjusting the $\mathrm{pH}$ value of the system were 5,6,7,8,9,10, and study on the effect of different $\mathrm{pH}$ values on the LAS removal efficiency of activated sludge.It can be seen from Figure 4 , the ability of $\mathrm{pH}$ to degrade LAS in 6-9 is better In these $6 \mathrm{pH}$ gradients, especially for $\mathrm{pH}=7$ degradation the maximum extent,the removal rate of LAS reached $74 \%$. This shows that when the $\mathrm{pH}$ value is equal to 7 ,the number of active groups of microorganisms in activated sludge microorganisms were largest, good growth, natural degradation ability of LAS. The microorganisms as measured in the sludge under the condition of its $\mathrm{pH} 7$ indicating that $\mathrm{pH}$ under the condition indicating that the Activated Sludge Microbes adapt to production in a neutral environment, have certain $\mathrm{pH}$ adjustment ability.

\subsection{The effects of aeration}

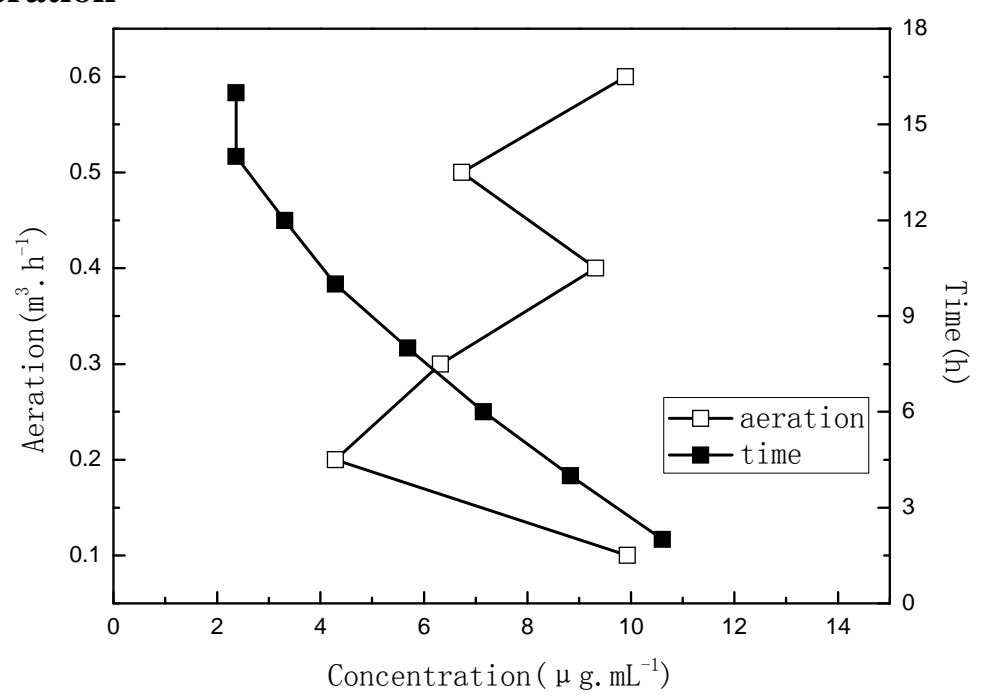

Fig.5 Influence of aeration condition on LAS removal efficiency

As shown in figure 5,the effect of aeration time and aeration rate on the degradation of LAS was researched, In the SBR system, with the aeration increasing, LAS degradation first increased and then decreased. As the aeration time increased, LAS concentration decreased gradually in the system, after the $12 \mathrm{~h}$ tends to be stable. The LAS concentration was $12.5 \mu \mathrm{g} \cdot \mathrm{mL}^{-1}$, $\mathrm{pH}$ value was 7 , the aeration is $0.2 \mathrm{~m}^{3} \cdot \mathrm{h}^{-1}$, the aeration time is $12 \mathrm{~h}$, the removal rate of LAS reached $81 \%$. 


\subsection{Effects of different metal ions}

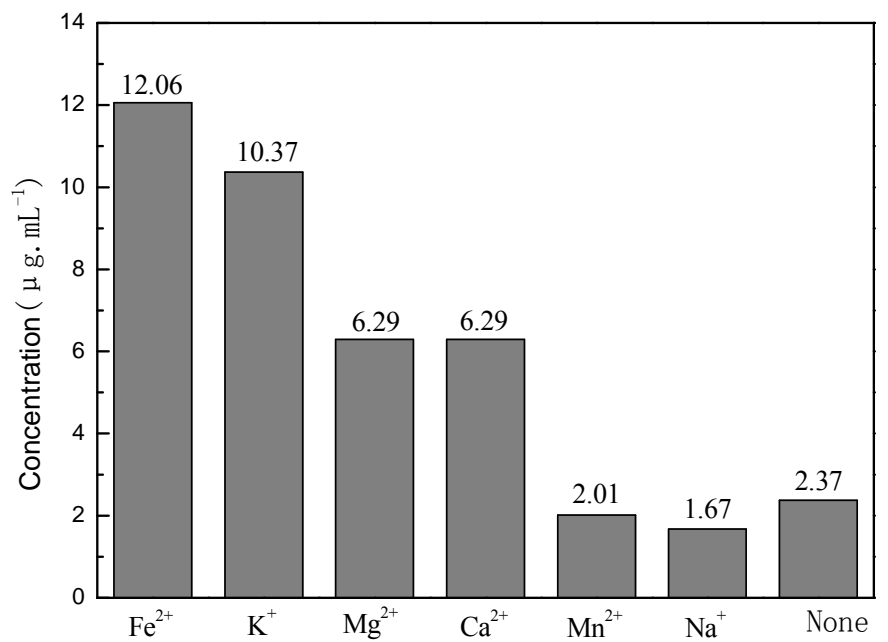

Fig.6 Influence of different metal ions on LAS removal efficiency

As shown in Figure $6, \mathrm{Fe}^{2+}, \mathrm{K}^{+}$had a significant inhibitory effect on the LAS degradation ability of activated sludge LAS (LAS removal rate were $4 \%$ and $17 \%$ ), $\mathrm{Mg}^{2+}, \mathrm{Ca}^{2+}$ had a slightly inhibitory effect on the LAS degradation ability of activated sludge LAS (LAS removal rate reached $50 \%$ ), $\mathrm{Mn}^{2+}, \mathrm{Na}^{+}$can promote the degradation of LAS(removal of LAS rates were $84 \%$ and $87 \%$ ). The above shows that, the metal ions has certain influence on the microorganism population survival and reputation. The concentration of metal ions in wastewater is controlled that can effectively improve the degradation ability to LAS of activated sludge.

\subsection{The kinetic parameters of equations}

In general, there are two viewpoints on the degradation kinetics of the substrate in SBR system: one is to Monod equation, which comply with the $\mathrm{V}=\mathrm{V}_{\max } \mathrm{S} /\left(\mathrm{K}_{\mathrm{s}}+\mathrm{S}\right)$; while another view is that, The zero order and first order reaction kinetics relationship were respectively in the influent and aeration period. This experiment discussed separately activated sludge degradation of LAS waste water, and push water artificial every day, So the Las concentration was used as substrate concentration directly , and to study the activated sludge organic matter degradation kinetics with Monod equation. At the beginning of the aeration, the degradation of LAS with Monod kinetics equation: $\mathrm{V}=\mathrm{V}_{\max } \mathrm{S} /\left(\mathrm{K}_{S}+\mathrm{S}\right)$.

In steady state, the LAS of internal reaction system is in the material balance equation, can be listed as follows:

$$
S_{0} Q-S_{\mathrm{e}} Q+\mathrm{v} \frac{\mathrm{d} S}{\mathrm{dt}}=0 \frac{X \mathrm{t}}{S_{0}-S_{\mathrm{e}}}=\left(\frac{K_{\mathrm{s}}}{\mathrm{v}_{\max }}\right) \quad\left(\frac{1}{S_{\mathrm{e}}}\right)+\frac{1}{\mathrm{v}_{\max }}
$$

Of which is the bacterial specific growth rate, unit is $\mathrm{d}^{-1}, \mathrm{~V}_{\max }$ is the maximum specific growth rate of bacteria, the unit with $\mathrm{d}^{-1}, \mathrm{~S}$ is the residual LAS concentration in the solution , $\mathrm{mg} \cdot \mathrm{L}^{-1} \cdot \mathrm{K}_{\mathrm{s}}$ is the half rate constant, that is the concentration of LAS when $\mathrm{V}=1 / 2 \mathrm{~V}_{\max }, \mathrm{mg} \cdot \mathrm{L}^{-1} \cdot \mathrm{S}_{\mathrm{e}}$ is the concentration of LAS remained in the system after the reaction time is t,he unit is $\mathrm{mg} \cdot \mathrm{L}^{-1}$, $\mathrm{Q}$ is the water flow, and unit is $\mathrm{L} \cdot \mathrm{h}^{-1}$.

the kinetic parameters of $\mathrm{V}_{\max }$ and $\mathrm{K}_{\mathrm{s}}$ were obtained by fit the data using Monod equation in this experiment. The fitting curve is shown in figure 7. 


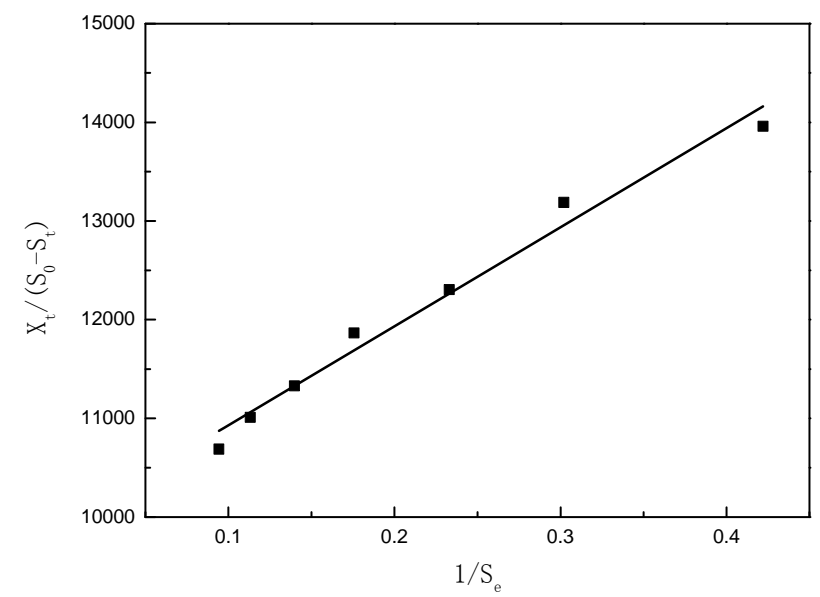

Fig. 7 Monod equation fitting graphs

As shown in figure 7,from the Monod equation fitting curve,the intercept $1 / \mathrm{V}_{\max }=9925.9$,slope $\mathrm{Ks} / \mathrm{V}_{\max }=10036, \mathrm{~V}_{\max }=1.01 \times 10^{-4} \mathrm{~d}^{-1}, \mathrm{~K}_{\mathrm{s}}=1.011 \mathrm{mg} \cdot \mathrm{L}^{-1}$, The activated sludge process LAS degradation kinetics equation of this experiment can be written as:

$$
\mathrm{v}=1.01 \times 10^{-4} \times \frac{X S}{1.011+S}
$$

In this experiment, degradation process of LAS by activated sludge accord with Monod equation, through the determination of the SBR system, the maximum specific degradation rate of $V_{\max }$ is $1.01 \times 10^{-4} \mathrm{~d}^{-1}$, the half rate constant $\mathrm{Ks}$ is $1.011 \mathrm{mg} \cdot \mathrm{L}^{-1}$. The degradation kinetics of activated sludge was researched, can provide a basis for the treatment of LAS waste water with the systems engineering design and theoretical research.

\section{Summary}

Through a series of experiments, the cultivation of the common activated sludge was accomplished, the effect of activated sludge on the degradation of LAS under different parameters was obtained,and the kinetic equation of LAS degradation was obtained by experimental data.In 4 Lactivated sludge, when the LAS concentration is $12.5 \mu \mathrm{g} \cdot \mathrm{mL}^{-1}$, the aeration capacity is $0.2 \mathrm{~m}^{3} \cdot \mathrm{h}^{-1}, \mathrm{pH}$ value is 7 ,reaction time is $12 \mathrm{~h}$, the best removal rate of LAS is $81 \%$.Activated sludge SV was stable at around $70 \%$. Activated sludge MLSS remained at about $10000 \mathrm{mg} \cdot \mathrm{L}^{-1}$, the growth activity of sludge was good and the activity was excellent. $\mathrm{Mn}^{2+}, \mathrm{Na}^{+}$made the treatment ability of activated sludge on LAS has improved significantly, the removal rate of LAS reached $84 \%$ and $87 \%$ respectively, $\mathrm{Fe}^{3+}, \mathrm{K}^{+}$, $\mathrm{Mg}^{2+}, \mathrm{Ca}^{2+}$ had significant inhibitory effect on activated sludge on LAS. The degradation kinetics equation of activated sludge on LAS can be written as: $v=1.01 \times 10^{-4} \times \frac{X S}{1.011+S}$

\section{Acknowledgments}

Fund: Talent introduction project from Sichuan University of Science \& Engineering (2016RCL40)

\section{References}

[1]. JU Hong-bin. Development trend of surfactant market. DETERGENT \& COSMETICS. Vol. 6(2014),p.1-6.

[2]. M. Hampel, I. Moreno-Garrido, E. González-Mazo, J. Blasco. Suitability of the marine prosobranch snail Hydrobia ulvae for sediment toxicity assessmentp. A case study with the anionic surfactant linear alkylbenzene sulphonate (LAS).Ecotoxicology and Environmental Safety. Vol.72 (2009),p. 1303-1308. 
[3]. Paul Henning Krogh, Coral Verge Lopez, Giorgio Cassani.Risk assessment of linear alkylbenzene sulphonates, LAS, in agricultural soil revisitedp. Robust chronic toxicity tests for Folsomia candida (Collembola), Aporrectodea caliginosa (Oligochaeta) and Enchytraeus crypticus (Enchytraeidae) Chemosphere. Vol.69 (2007),p. 872-879.

[4]. L.I.N.Ezemonye.Lethal toxicity of industrial detergent on bottom dwelling sentinels.International Journal of Sediment Research Vol.24 (2009) No.4,p.79-483.

[5]. ZhangTing,Feng Huixia,Zhang Juan,Yuan Xiaowei. Experimentof Fenton-Like Fe203/H202 Reaction Process for Treatment of Wastewater with Anionic Surfactant. Water Purification Technology Vol.32 (2013),p.39-42.

[6]. A. Mauffret, D.C. Gillan, K.M. Eriksson. LAS degradability by marine biofilms derived from seawater in Spain and Sweden. Ecotoxicology and Environmental Safety Vol.74 (2011),p. $1250-1256$.

[7]. Wang Kai, Wang Shuying, Zhu Rulong.Advanced nitrogen removal from landfill leachate without addition of external carbon using a novel system coupling ASBR and modified SBR.Bioresource Technology Vol.3(2013),p.212-218.

[8]. J. Gabarró, E. Hernández-del Amo, F. Gich.Nitrous oxide reduction genetic potential from the microbial community of an intermittently aerated partial nitritation SBR treating mature landfill leachate[J ].Water Research Vol.47(2013),p.7066-7077.

[9]. Yu Xiao Cai, Xu Wei. Environmental Treatment of Wastewater Containing Anion Surfactant with SBR Process .Environmental Science Vol.32 (2006),p.32-35.

[10]. Benjamin Ricken, Oliver Fellmann, Hans-Peter E. Kohler. Degradation of sulfonamide antibiotics by Microbacterium sp. strain BR1 - elucidating the downstream pathway.New Biotechnology. Vol.32 (2015), No.6, P.710-715.

[11]. Tiyasha Kanjilal, Chiranjib Bhattacharjee, Siddhartha Datta. Bio-degradation of acetamiprid from wetland wastewater using indigenous Micrococcus luteus strain SC 1204p. Optimization, evaluation of kinetic parameter and toxicity.Journal of Water Process Engineering Vol.6 (2015),p.21-31.

[12]. Bokun Lin, Jinling Lyu, Xian-jin Lyu, Han-qing Yu. Characterization of cefalexin degradation capabilities of two Pseudomonas strains isolated from activated sludge.Journal of Hazardous Materials Vol.282 (2015),p. 158-164.

[13]. Aamer Ali Shah, Ahmed Nawaz, Lubna Kanwal.Degradation of poly( $\varepsilon$-caprolactone) by a thermophilic bacterium Ralstonia sp. strain MRL-TL isolated from hot spring.International Biodeterioration \& Biodegradation. Vol.98(2015),p. 35-42. 